\title{
Performance Analysis of Different PV Array Configurations under Partial Shading
}

\author{
Uday Singh Rawat ${ }^{1}$, Ravi Saxena ${ }^{2}$
}

\begin{abstract}
In recent years growing concerns on energy sustainability and security have introduced significant research efforts on the penetration of Renewable Energy Sources (RES) into present electric power system. Photovoltaic (PV) energy is the most important RES since it is clean, pollution free, and inexhaustible. Solar photovoltaic (PV) arrays in portable applications are often subjected to partial shading and rapid fluctuations of shading. The main objective of this paper is to analyze the effect of partial shading on the maximum power point of various solar photo voltaic array (SPVA) configuration. It is very difficult and costly to conduct the experiment on various array sizes. A MATLAB/SIMULINK based solar module is developed for any required array size, configuration and shading pattern. The proposed model provides sufficient degree of precision without increasing computational effort. Comparative study has been performed on different configuration for various shading patterns on the basis of various partial shading losses and fill factor to investigate which configuration is less prone to various power losses under partial shading condition (PSC).
\end{abstract}

Keyword- Partial shading, Bypass diode, Mismatch loss, Fill factor, MATLAB/SIMULINK

Uday Singh Rawat, M. Tech

G.B.P.U.A.\&T., Uttarakhand

India

Ravi Saxena, Ph. D.

G.B.P.U.A.\&T., Uttarakhand

India

\section{Introduction}

The ever increasing demand for low cost energy and growing concern toward the utilization of renewable energy sources such as solar energy. The freely and abundantly available solar energy can be easily converted into electrical energy by using photo voltaic cell [5].In the recent year the advancement of smart grid theory as acted as a spur for the wide spread of Photo Voltaic (PV) system. PV cells are connected in series and parallel to meet the requisite demand of voltage level and power. Solar insolation, temperature and output voltage are the essential factors that affect the output characteristic of the PV cell [2].Solar PV panel is a power source having nonlinear internal resistance.

A major challenge in using a SPV source containing a number of cells in series is to deal with its non-linear internal resistance. The performance is adversely affected if all its cells are not equally illuminated. All the cells in a series array are forced to carry the same current even though a few cells under shading produce less photon current. The shaded cells may get reverse biased, acting as loads, draining power from fully illuminated cells [3]-[4]. If the system is not appropriately protected, hotspot problem (premature failure problem) can emerge and in several cases, the system can be irreversibly damaged. The series connection of PV cells is subjected to mismatch power losses if the electrical characteristics of the PV cells are not identical. The PV cell with the lowermost short circuit (SC) current limits the current of the whole series connection [9].To prevent PV cell from being damaged due to hot spot bypass diode are connected in antiparallel with PV cell. The bypass diode across the shaded group of cells will conduct when shading causes a cell to go far enough into reverse bias. The bypass diode allows current from non-shaded parts of the module to pass by the shaded part and limits the effect of shading to the only neighboring group of cells protected by the same bypass diode. When a bypass diode begins conducting, the module voltage will drop by an amount corresponding to the sum of cell voltages protected by the same bypass diode plus the diode forward voltage, but current from surrounding unshaded groups of cells continues around the group of shaded cells. The effect of shade on power output of typical PV installation is nonlinear in that a small amount of shade on a portion of an array can cause a large reduction in output power [10]-[11]

The major reason for the uneven short circuit current is the partial shading of the PV power generator due to cloud, near by trees and buildings, overhead cables etc. Shading obstruction can be soft or hard source. If a tree branch, roof vent, chimney or other item is shading from distance, the shadow is diffused or dispersed. These soft sources significantly reduce the amount of light reaching the cell(s) of a module. Hard sources are defined as those that stop light from reaching the cell(s), such as a blanket, tree, branch, bird dropping, or the like, sitting directly on top of the glass. In this paper, the hard sources are analyzed as it highly affects the performance of module [8]. In recent years, the impact of partial shading on the PV array performance has been widely discussed. With the physical 
SPVA it is difficult to study the effects of partial shading since field testing is expensive and time consuming and moreover it is difficult to maintain constant shading condition throughout the experiment hence it is easy and convenient to carry out the simulation study in MATLAB/SIMULINK model.

\section{II. $\quad$ PV Module Modelling}

The PV module is the interface which converts light into electricity. Modeling this device necessarily requires taking weather data (irradiance and temperature) as input variables. The output can be current, voltage, power or other [12], [15] and [16]. PV cells are grouped in larger units called PV modules which are further interconnected in a parallel-series configuration to form PV arrays.

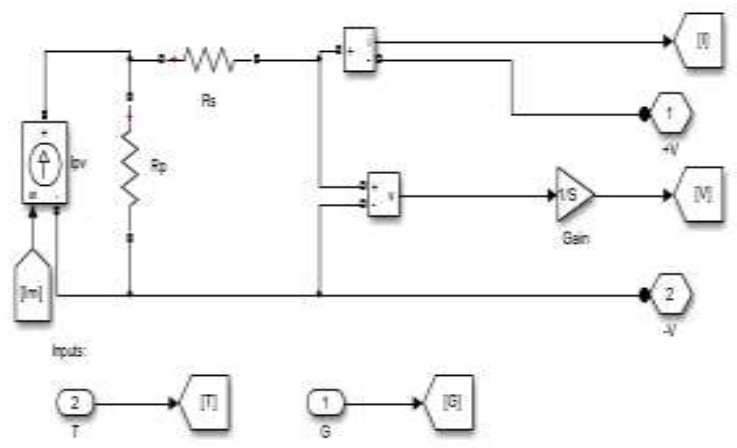

Figure 1 Simulink based model of generalized PV array

a) Module photo-current:

$$
\mathrm{I}_{\mathrm{PH}}=\left[\mathrm{I}_{\mathrm{SCR}}+\mathrm{K}_{\mathrm{i}}\left(\mathrm{T}_{\mathrm{K}}-\mathrm{T}_{\mathrm{Ref}}\right)\right] * \frac{\lambda}{1000}(1)
$$

b) Module reverse saturation current:

$$
I_{r S}=\frac{I_{S c}}{\left[\exp \left(\frac{q V o c}{N s k A T}\right)-1\right]}
$$

c) Module saturation current:

$$
\mathrm{I}_{\mathrm{O}}=\mathrm{I}_{\mathrm{RS}}\left[\frac{\mathrm{T}}{\mathrm{T}_{\mathrm{r}}}\right]^{3} \exp \left[\frac{\mathrm{q} * \mathrm{E}_{\text {go }}}{\mathrm{AK}}\left\{\frac{1}{\mathrm{~T}_{\mathrm{r}}}-\frac{1}{\mathrm{~T}}\right\}\right]
$$

d) Current output of PV module:

$$
\mathrm{I}_{\mathrm{PV}}=\mathrm{N}_{\mathrm{P}} \mathrm{I}_{\mathrm{PH}}-\mathrm{N}_{\mathrm{P}} \mathrm{I}_{0}\left[\exp \left(\frac{q *\left(V_{P V}+I_{P V} R_{S}\right)}{N_{S} A K T}\right)-1\right]
$$

Since Matlab/Simulink has powerful tool box for modeling the power system and power electronics components, hence to interface the mathematical PV model with the power system tool box, the PV model output current has been fed to a DC controlled current source and the output voltage has been measured then fed back into the voltage input of the PV panel. The circuit showing in figure (1) has been transformed into a subsystem that is masked with a PV array icon so that it can be easily implemented with any power system toolbox simulation. As observed in Fig. (2).

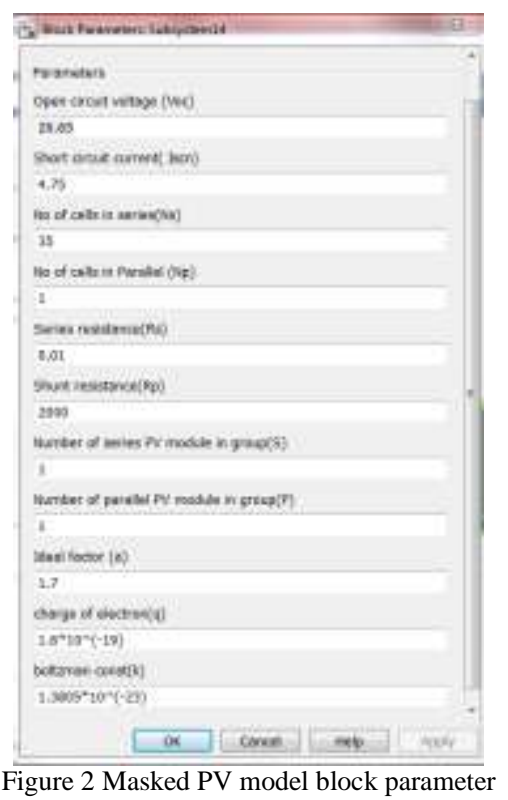

\section{Shading Losses}

The MPP of the PV array does not match with the MPP of the individual modules under partial shading condition (PSC). Various power losses due to PS are illustrated in fig. (3). The maximum possible power under partial shading (PS) is the sum of the maximum powers of the individual modules when operating independently under the same solar insolation. Obviously, array maximum power without partial shading is always more than the maximum possible power under PS. The difference between the two powers, mismatch loss is a distinctive property of each generator configuration. Mismatch loss of the PV generator is calculated by comparing the power of the global MPP to the sum of the maximum power of the individual modules under PS conditions. The mismatch loss represents the lost power owing to the fact that the PV modules do not operate at its own MPP, although the whole PV generator operates at its GMPP [1]. Mismatch loss is depicted by

$$
P_{\text {mismatch loss }}=P_{\max (\text { unshaded })}-P_{\max (\text { shaded })}
$$

Loss of power due to PSC can also be defined in term of Fill Factor

$$
\mathrm{FF}=\frac{\mathrm{G}_{\mathrm{MPP}}}{\mathrm{V}_{\mathrm{OC}} \times \mathrm{I}_{\mathrm{SC}}}
$$

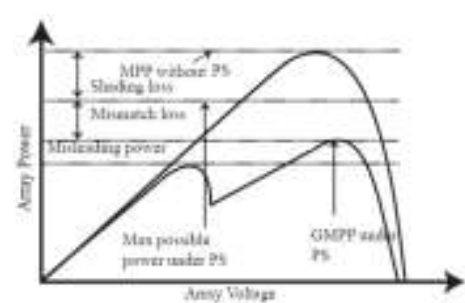

Figure3. Various losses under PSC 


\section{Iv. Review of SPVA Configuration}

Practically partial shade has great impact on larger arrays. For understanding the practical cases, it is required to go for larger arrays with different configurations. There are several SPVA configuration which have been proposed in the literature as shown in figure (4)[13],[14].They are series, parallel, series parallel (SP), Bridge linked (BL), honey comb (HC) and total cross tied (TCT). Series and parallel configurations are the basic configurations and the performance of these configurations has been discussed in detail .The major drawbacks of using the series or parallel configuration are that the current and voltage is less respectively. In $\mathrm{BL}$ configuration the modules are interconnected as in a bridge approach. Two modules in a bridge are linked in series and then they are connected in parallel. Bridges are interconnected through ties. TCT configuration has been derived from SP by interconnecting the rows of the junction through ties. In TCT, voltage across the various ties and the sum of the currents through various ties are equal. The BL configuration has been adapted to get the HC configuration.
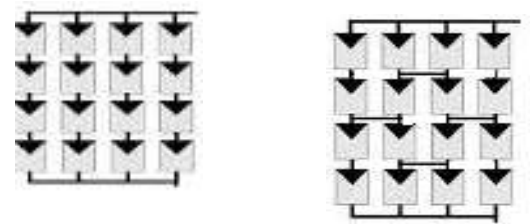

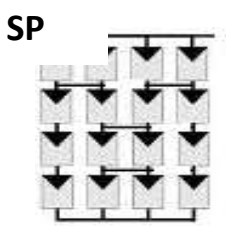

HC
BL

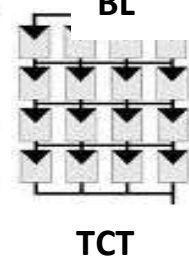

Fig 4. Different Array Configuration

The TCT configuration is derived from the SP configuration by connecting ties across the rows of the junction.IN the TCT voltage across the ties are equal. The sum of current across various ties is equal.

\section{v. Simulation and Performance Comparison}

In this section a comparison is made among the different array configuration of different array size in term of root mean square deviation (RMSD), average value of power, mismatch loss (ML) and fill factor (FF). The array sizes are $2 \times 2,3 \times 3,3 \times 4,4 \times 3,4 \times 4,6 \times 4$ and $4 \times 6.6$ different shading patterns are created for each seven array size. Power, voltage, mismatch loss, fill factor, RMSD and mean power is calculated for each array size at each shading patterns.

\section{Result and Discussion}

In this paper result is shown for $3 \mathrm{X} 3$ and $4 \mathrm{X} 4$ array and similar results are obtained for rest of the arrays.

\section{A. Mismatch loss}

Mismatch loss is the difference between the sum of individual maximum power under partial shading condition and the GMPP. From eq. (5) [6]

$$
P_{\text {mismatch loss }}=P_{\max (\text { unshaded })}-P_{\max (\text { shaded })}
$$

Figure (6) and (7) shows the mismatch loss of four different configurations.
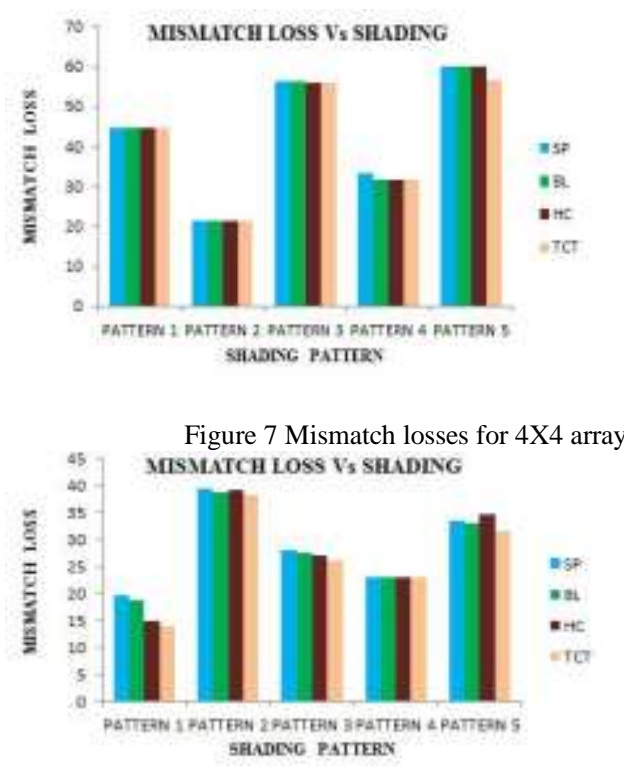

Figure 8 Mismatch loss for $3 \mathrm{X} 3$ array

Fill Factor

Losses due to PS cause reduction in fill factor. The FF reduces harshly as the shading increase. The influence of bypass diode has significant impact on TCT configuration. Figure (9) and (10) shows the variation in FF for four configurations

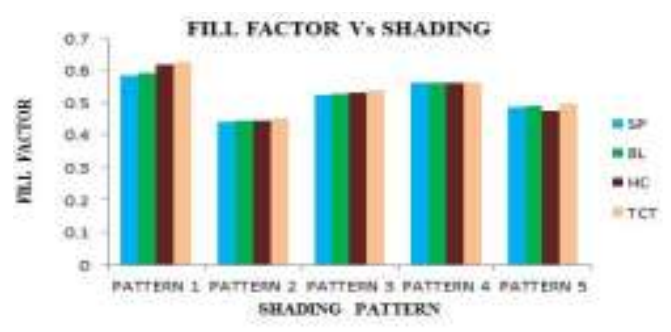

Figure 9 Fill Factor for $4 \mathrm{X} 4$ array 


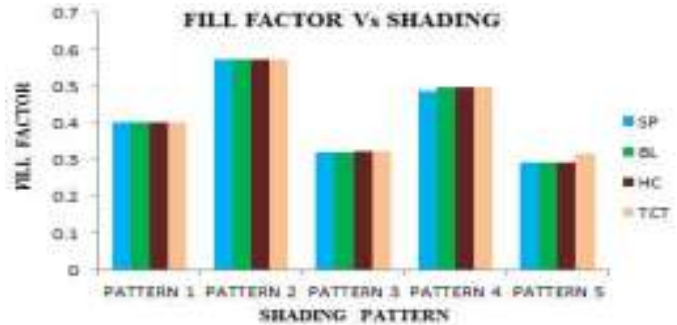

Figure 10 Fill Factor for 3X3 array

\section{B. Root mean square deviation}

RMSD is calculated for each configuration by primarily subtracting the uniform irradiance value from the partial shaded value. These values are squared and then the square root of its average is obtained. This gives the RMSD value for a configuration of a particular size [7].

$R M S D=\sqrt{\frac{\sum_{i=1}^{n}(\operatorname{Pmax}(\text { unshade })-P \max (\text { shade }))^{2}}{n}}$

Figure (11) and (12) shows TCT has least RMSD for each shading pattern in each array size.

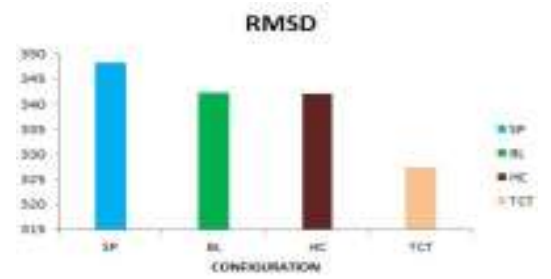

Figure 11 RMSD for $4 \mathrm{X} 4$ array

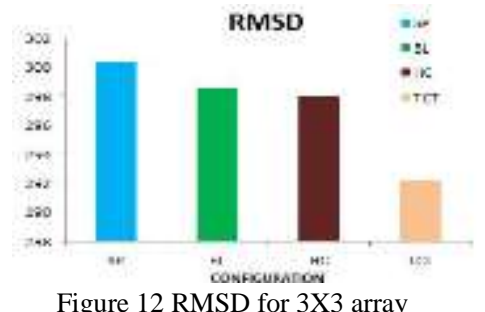

C. Average Power

Average power is calculated from equation (7). Figure (13) and (14) show TCT configuration produces maximum average power.

$$
\text { Avg. Power }=\frac{\sum_{i=1}^{n} P_{\max (\text { unshaded })}}{n}
$$

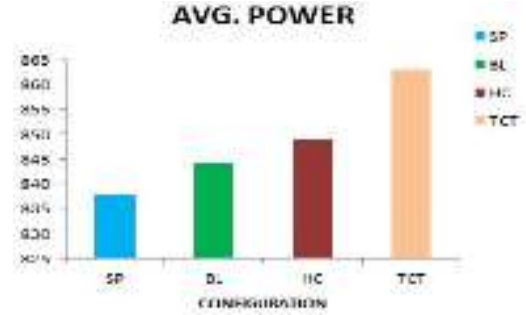

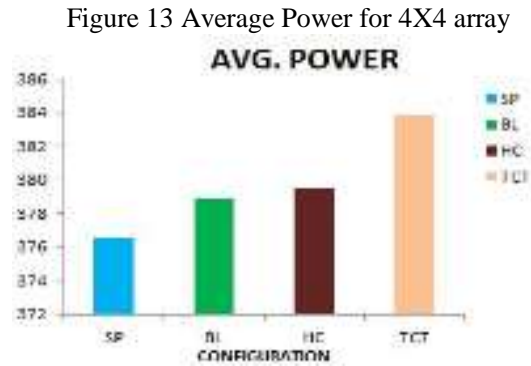

Figure14 Average Power for 3X3 array

Figure (15) and (16) shows the PV curve for $4 \mathrm{X} 4$ and $3 \mathrm{X} 3$ array respectively.
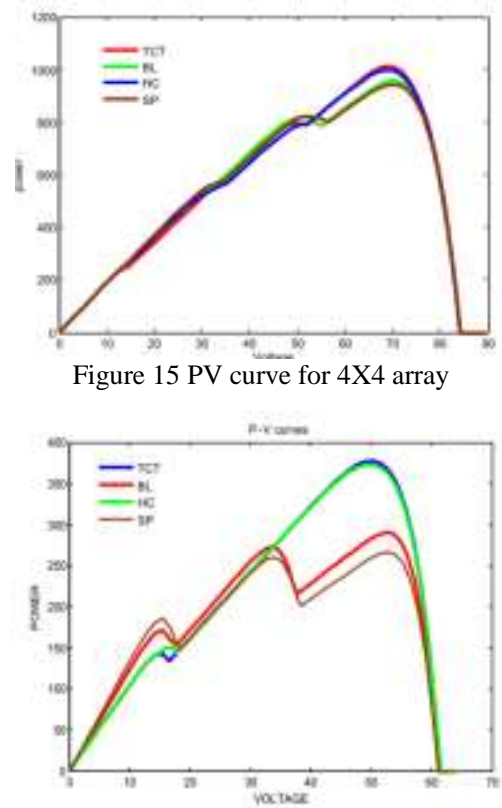

Figure $16 \mathrm{PV}$ curve for $3 \mathrm{X} 3$ array

The power and voltage value for each configuration is calculated for each configuration of each array size at each shading pattern. Table 1 shows the comparison of RMSD in power and average power of for each configuration of each array size.

\section{vII. Conclusion}

This paper analyzes the various configuration of SPVA in different environmental partial shading condition. To perform the simulation, a MATLAB /SIMULINK based PV module is developed which is capable of simulating any number of module connected in series or parallel and any type of shading pattern. To prevent the hot spot problem and to get maximum power bypass diode is connected in antiParallel with shaded module

The impact of PS SP, BL, HC, TCT configuration have analyzed in terms of mismatch loss, fill factor, RMSD of power and average power for eacharraySizes. Result shows that TCT configuration is least prone to PS losses. Thispaper 
investigatethat TCTConfiguration gives optimum result under partial Shading condition.

Table 1comparison of rmsd and average power of different configurations with different sizes

\section{x. References}

[1] E. Suryanto Hasyim, S.R., Wenham and M.A. Green, "Shadow toterance of modules incorporationg integral bypass diode solar cells", Solar Cells, Vol. 19, March 19, 1986, pp109-112.

[2] Habbati Bellia, Ramdani Youcef, Moulay Fatima "A detailed modeling of photovoltaic module using MAT LAB" National Research Institute of Astronomy and Geophysics (2014) 3, 53-61

[3] Appelbaum, J., Bany, J., "Shadow effect of adjacent solarcollectors in large scale systems", Solar Energy 23, 1979, 497-507.

[4] A Bete, A., Barbisio, E., Cane, F., "A study of shading effects in photovoltaic generators". Proceedings of the 9th EC PVSolar Energy Conference, Freiburg, 1989, pp. 240-244

[5] .venkateswarlu,C.H. Jhansi and P.S.Raju 'fuzzy logic based maximum power point tracking technique for partially shaded photovoltaic system' International journal of Electrical and Electronics Engineering

[6] S Vijayalekshmy, R G Bindu, and Iyer S Rama 2014"Estimation of Power Lossesin Photovoltaic Array Configurations under Passing Cloud Conditions'Proceedings of the World Congress on Engineering 2014 Vol I,

[7] Ramaprabha, R. 2014" Selection of an Optimum Configuration of Solar PV Array under Partial Shaded Condition Using Particle Swarm Optimization" World Academy of Science, Engineering and TechnologyInternational Journal of Electrical, Computer, Electronics and Communication Engineering Vol:8, No:1

[8] Hla Hla Khaing, Yit Jian Liang, Nant Nyein Moe Htay, Jiang Fan "Characteristics of Different Solar PV Modules under Partial" shading International Journal of Electrical, Computer, Electronics and Communication Engineering Vol:8, No:9, 2014

[9] Ramabadran, Ramaprabha Mathur, Badrilal 2009 "Effect of Shading on Seriesand Parallel Connected Solar PV Modules" www.ccsenet.org/journalorg

Diaz-Dorado, A. Suarez-Garcia, C. Carrillo and J. Cidras, "Influence of the Shadows in Photovoltaic Systems with Different Configurations of Bypass Diodes," 2010 International Symposium on Power Electronics ElectricalDrives Automation and Motion (SPEEDAM), Pisa, 14-16 June 2010, pp. 134-139.

[10] C. Deline, "Partially Shaded Operation of a Grid-Tied pv System," 34th IEEE Photovoltaic Specialists Conference, Philadelphia, 7-12 June 2009.

[11] ]Basim A. Alsayid, Samer Y. Alsadi, Ja'far S. Jallad, Muhammad H. DradiPartial Shading of PV System Simulation with Experimental Results.

[12] Kaushika.N.D and gautan N.K.,"Energy yield simulationof interconnected solar PV array",IEEE Transaction on Energy Conversion 2003, 18(1) pp127-134

[13] Gonzalez.C and Weaver.P."Circuit design consideration of photovoltaic moduleand systems", $14^{\text {th }}$ IEEE photovoltaic specialist conference, 1980,pp528-535

[14] Samer Said, Ahmed Massoud, Mohieddine Benammar and Shehab Ahmed"A Matlab/Simulink-Based Photovoltaic Array Model Employing SimPowerSystems Toolbox"Journal of Energy and Power Engineering 6 (2012) 1965-1975

[15] Krismadinataa, Nasrudin Abd. Rahima Hew Wooi Pinga, Jeyraj Selvaraja "Photovoltaic module modeling using simulink/matlab"

\begin{tabular}{|l|l|l|l|}
\hline \multirow{2}{*}{$\begin{array}{c}\text { ARRAY } \\
\text { SIZE }\end{array}$} & \multirow{2}{*}{$\begin{array}{c}\text { CONFI- } \\
\text { URATION }\end{array}$} & \multicolumn{2}{|c|}{$\begin{array}{c}\text { MAXIMUM } \\
\text { POWER }\end{array}$} \\
\cline { 3 - 5 } & & $\begin{array}{c}\text { MEAN } \\
\text { VALUE }\end{array}$ & RMSD \\
\hline 2 X2 & SP & 156.84 & 137.93 \\
\hline $\mathbf{2 \times 2}$ & TCT & $\mathbf{1 6 3 . 1 0}$ & $\mathbf{1 3 1 . 4 8}$ \\
\hline $3 \times 3$ & SP & 376.58 & 300.34 \\
\hline $3 \times 3$ & BL & 378.90 & 298.53 \\
\hline $3 \times 3$ & HC & 379.44 & 297.98 \\
\hline $\mathbf{3 \times 3}$ & TCT & $\mathbf{3 8 3 . 8 6}$ & $\mathbf{2 9 2 . 1 6}$ \\
\hline $4 \times 3$ & SP & 552.64 & 333.66 \\
\hline $4 \times 3$ & BL & 570.44 & 316.78 \\
\hline $4 \times 3$ & HC & 555.64 & 330.83 \\
\hline $\mathbf{4 \times 3}$ & TCT & $\mathbf{5 7 5 . 3 6}$ & $\mathbf{3 1 2 . 4 2}$ \\
\hline $3 \times 4$ & SP & 508.96 & 388.95 \\
\hline $3 \times 4$ & BL & 517.46 & 383.30 \\
\hline $3 \times 4$ & HC & 508.52 & 388.66 \\
\hline $\mathbf{3} \times \mathbf{4}$ & TCT & $\mathbf{5 2 2 . 3 4}$ & $\mathbf{3 7 9 . 5 8}$ \\
\hline $4 \times 4$ & SP & 837.86 & 348.23 \\
\hline $4 \times 4$ & BL & 844.08 & 342.20 \\
\hline $4 \times 4$ & HC & 848.90 & 342.07 \\
\hline $\mathbf{4} \times \mathbf{4}$ & TCT & $\mathbf{8 6 2 . 8 8}$ & $\mathbf{3 2 1 . 3 1}$ \\
\hline $4 \times 6$ & SP & 1078.87 & 734.23 \\
\hline $4 \times 6$ & BL & 1107.50 & 700.59 \\
\hline $4 \times 6$ & HC & 1096.67 & 712.92 \\
\hline $\mathbf{4} \times \mathbf{6}$ & TCT & $\mathbf{1 1 1 7 . 8 7}$ & $\mathbf{6 8 8 . 9 5}$ \\
\hline $6 \times 4$ & SP & 1072.80 & 697.26 \\
\hline $6 \times 4$ & BL & 1092.50 & 678.18 \\
\hline $6 \times 4$ & HC & 1078.40 & 694.24 \\
\hline $\mathbf{6} \times \mathbf{4}$ & TCT & $\mathbf{1 0 9 7 . 8 3}$ & $\mathbf{6 7 4 . 1 8}$ \\
\hline
\end{tabular}

\section{BIOGRAPHIES}

Uday Singh Rawat received B.Tech degree in Electrical Engineering from Uttarakhand Technical University, Dehradun, India in 2013 and received his M.Tech degree in Electrical Energy System from G.B.P.U.A \& T, Pantnagar in 2015.

Ravi Saxena received B.Tech, M.Tech and Ph.D degrees in Electrical Engineering from G. B. Pant University of Agriculture \& Technology, Pantnagar, India in 1993, 1996 and 2012 respectively. Presently he is working as Associate Professor- REC Chair in the department of Electrical Engineering at College of Technology, Pantnagar. His main scientific interests are in the fields of power quality, power system and non-conventional energy sources. 